\title{
КОЛИЧЕСТВЕННАЯ ПЕТРОГРАФИЯ КАК ОСНОВА ПОСТРОЕНИЯ ГЕОЛОГИЧЕСКИХ МОДЕЛЕЙ КАРБОНАТНЫХ РЕЗЕРВУАРОВ
}

\author{
М. А. Тугарова, Е. Н. Максимова, С. А. Идрисова \\ ООО «Газпромнефть НТЦ», г. Санкт-Петербург \\ Поступила в редакцию 10 июня 2019 г.
}

\begin{abstract}
Аннотация: построение любой геологической модели базируется на детальном описании керна, определении вещчественно-структурных признаков пород и их корреляции с данными других исследований. В качестве основы для построения литолого-седиментационных моделей карбонатных резервуаров предложен шаблон представления результатов петрографического анализа в числовом виде. Разработан алгоритм обработки петрографических данных и их корреляции с петрофизическими параметрами. Предлагаемая методика позволяет проводить выделение литотипов на основе количественных параметров вещественно-структурных признаков пород, выделять значимые фациальные признаки пород и литогенетические процессы, влияющие на фильтрационно-емкостные параметры, создавая объективную базу для построения концептуальных и $3 D$ моделей.
\end{abstract}

Ключевые слова: петрография, структура, состав, вторичные процессы, фильтрационноемкостные свойства, геологическая модель

\section{QUANTITATIVE PETROGRAPHY AS A BASIS FOR THE GEOLOGICAL MODELING OF CARBONATE RESERVOIRS}

\begin{abstract}
: the construction of any geological model is based on a detailed core description, determining the mineral composition and structural features of rocks and their correlation with the other studies data. As a basis for the models of carbonate reservoirs, a template for presenting petrographic analysis results in numerical form has been proposed. An algorithm for processing petrographic data and their correlation with petrophysical parameters has been worked out. The proposed method allows lithotypization on the basis of quantitative mineral parameters and structural features of rocks, helps to distinguish significant facial signs of rocks and lithogenetic processes affecting reservoir parameters, creating an objective basis for constructing conceptual and $3 D$ models.
\end{abstract}

Key words: petrography, structure, composition, secondary processes, reservoir

Введение

Построение цифровых геологических моделей продуктивных резервуаров в настоящее время является обязательной процедурой при планировании геологоразведочных и эксплуатационных работ. Повышение достоверности прогноза залежей углеводородов (УВ), разработка геолого-технических мероприятий требует качественной интерпретации геологических, геофизических, геохимических и литологических данных и возможность цифрового комплексирования информации. При использовании широкого комплекса методов, результаты литологических исследований занимают особое место, так как именно прямые данные о вещественно-структурных признаках пород являются основой для создания концептуальной модели рассматриваемого объекта и обуславливают методологические подходы, используемые для построения куба литологии в $3 \mathrm{D}$ геологической модели.
Построение любой литологической модели базируется на детальном описании керна, лабораторных анализов определений вещественно-структурных признаков пород (прежде всего, петрографический анализ) и данных геофизических исследований скважин (ГИС). Фациальная (седиментационная) модель предусматривает оценку первичных признаков пород, а литологическая модель должна отражать совокупность первичных и постседиментационных преобразований, которые и обуславливают неоднородность фильтрационно-емкостных свойств (ФЕС) карбонатных коллекторов. Таким образом, конечной целью литологического моделирования должна являться типизация пород резервуара по коллекторским свойствам и оценка роли геологических процессов, определяющих формирование продуктивной части резервуара.

Для терригенных резервуаров известны примеры разработки удачных схем построения седиментаци- 
онных моделей [1]. В моделировании карбонатных резервуаров, по сравнению с терригенными, наметилось определенное отставание. Во многом это связано с тем, что данные о структурах карбонатных пород имеют менее выраженную возможность перевода в цифровой формат. С другой стороны, карбонатные породы, содержащие цельноскелетную фауну или биодетрит, часто оказываются более информативными при диагностике обстановок осадконакопления.

В настоящее время построение литолого-седиментационных моделей карбонатных резервуаров часто проводится на качественном уровне, выделение числовых объективных признаков, отражающих литотип или фацию, приводятся редко, в результате подобные модели часто формальны и не несут информативной нагрузки в геологических моделях резервуаров. Цель разработанной методики - упростить и оптимизировать выделение фаций карбонат- ных отложений на основе числовых петрографических данных и одновременно установить корреляцию вещественных признаков пород с их фильтрационно-емкостными свойствами.

\section{Методика работ}

В качестве основы для построения литологических моделей карбонатных резервуаров предложен шаблон представления результатов петрографического анализа в формате таблицы Excel (рис. 1). Подобный табличный подход выполнения петрографического анализа впервые был предложен во ВНИГРИ [2]. Современные возможности компьютерных технологий позволяют широко использовать числовые форматы характеристик вещественно-структурных признаков пород в процедурах формализованного описания неоднородностей резервуара, обусловленных литологическими особенностями пород продуктивных пластов.

Первый блок шаблона включает признаки пород,
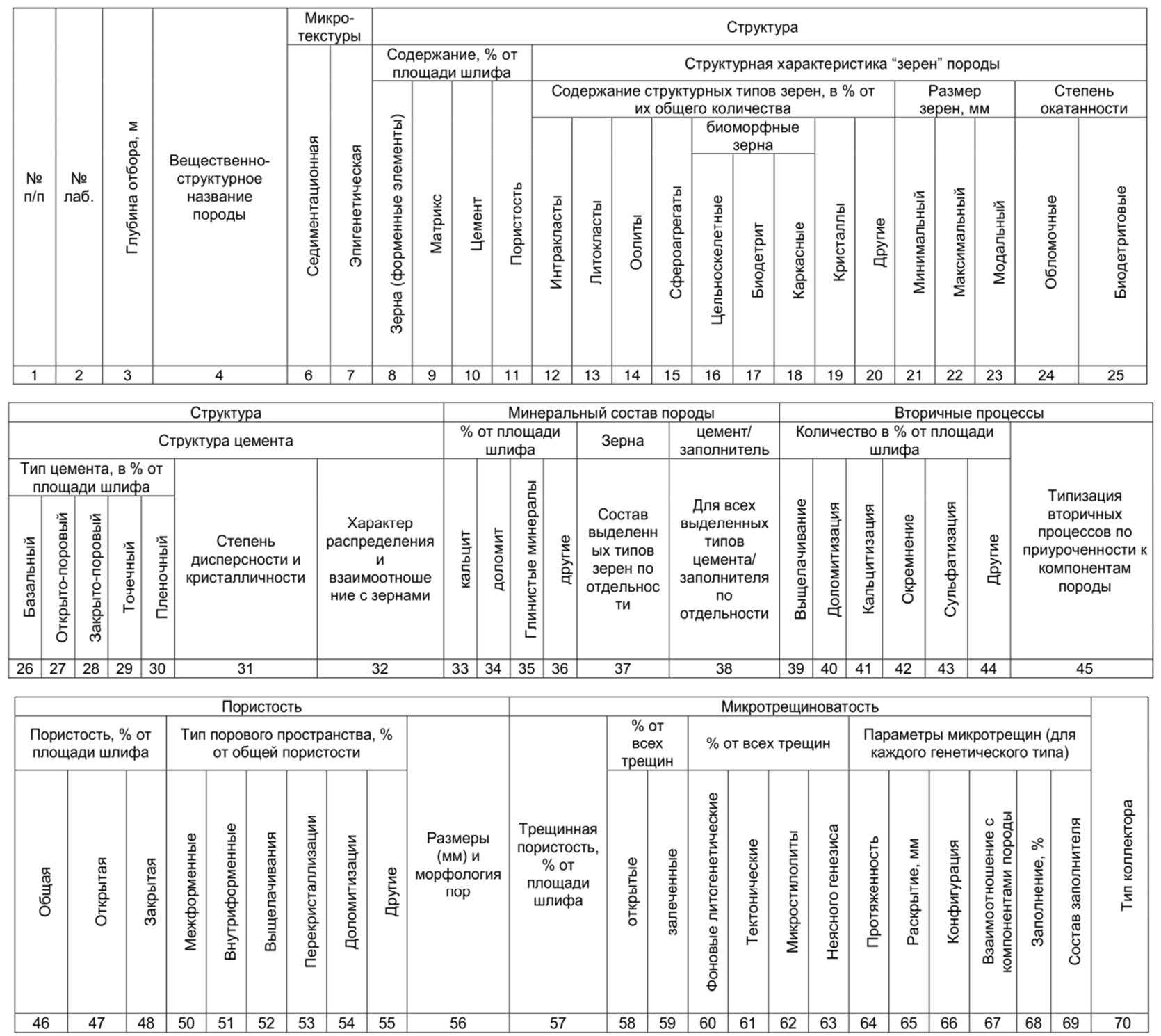

Puc. 1. Шаблон количественного петрографического описания карбонатных пород. 
характеризующие их основные структурные параметры (рис. 1, пп. 8-32). В процентах от площади шлифа оцениваются содержания форменных элементов в структуре породы («зерен»), микритового заполнителя, цемента, пустотного пространства. Уже эти показатели могут отражать изменения коллекторских свойств карбонатных пород. Последующая детализация содержаний форменных элементов разного генетического типа (интракласты, оолиты, детрит и др.) позволяет переходить на интерпретацию фаций. Размерность карбонатных зерен и их окатанность не являются ключевыми признаками, т.к. определяются не только гидродинамикой среды осадконакопления, но и, например, крепостью скелета того или иного организма, но иногда бывают полезными параметрами при оценке условий седиментации. В этой же части шаблона дается количественная характеристика цемента или нескольких цементов, степени их дисперсности, кристалличности и характера взаимодействия с форменными элементами породы. Совокупное изменение структурных характеристик пород по разрезу позволяет прослеживать смену условий и обстановок осадкообразования.

Во втором блоке шаблона (рис. 1, пп. 33-45) дается количественная оценка минерального состава породы и детально (в \% от площади шлифа) характеризуются вторичные процессы: выщелачивание, перекристаллизация, доломитизация и др. Далее в описательном варианте приводится типизация вторичных процессов по приуроченности к компонентам породы и кратко рассматривается стадиальная схема вторичных процессов. Числовая оценка вторичных процессов позволяет выявлять тенденции постседиментационных изменений по разрезу и по латерали, а, следовательно, и прогнозировать качество карбонатных коллекторов.

Третий блок шаблона (рис. 1, пп. 46-56) предусматривает характеристику порового пространства: равномерность/неравномерность распределения пор, значения общей, открытой, закрытой пористости, модальная размерность пор и соотношение (в \%) разных типов порового пространства - седиментационных и эпигенетических.

Для коллекторов сложного типа принципиально важна характеристика параметров микротрещиноватости. Этим параметрам посвящен четвертый блок шаблона (рис. 1, пп. 57-69). В случае наличия в породах нескольких систем микротрещиноватости проводится количественная оценка для каждой из систем микротрещин.

Простейший алгоритм применения числовых петрографических данных может быть представлен алгоритмом, показанным на рис. 2.

Таким образом, создается числовая основа, всесторонне характеризующая карбонатные породы, которую удобно использовать при анализе петрографической информации по керну, сопоставления литологических и петрофизических данных.

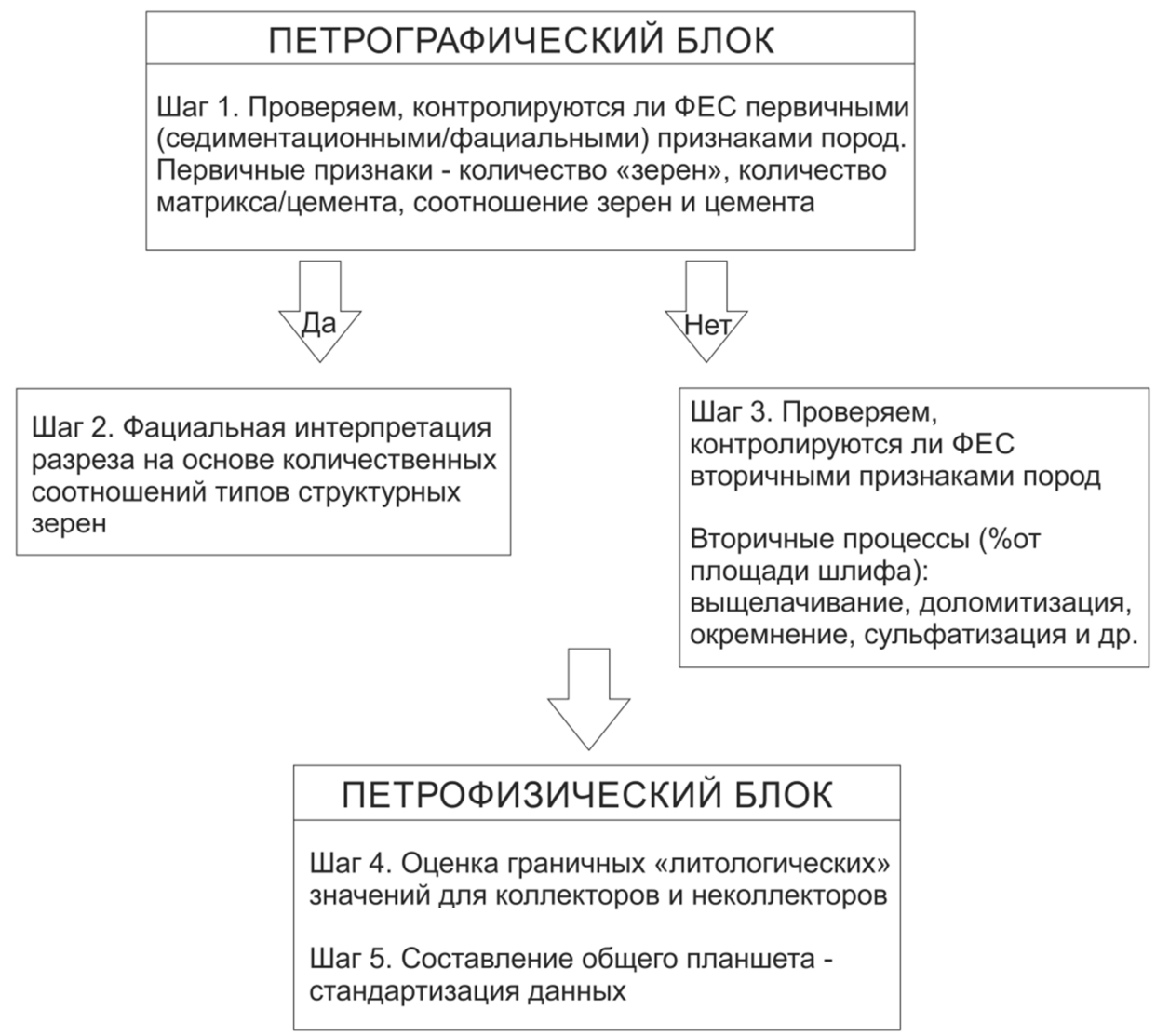

Puc. 2. Алгоритм использования числовых петрографических данных в системе геологического моделирования 


\section{Интерпретация карбонатных разрезов}

Приведем несколько примеров, иллюстрирующих применение количественных петрографических данных. На первом этапе анализа информации рекомендуется проверять, коррелируют ли ФЕС с первичными (седиментационными/фациальными) признаками пород. В качестве «литологического» параметра в этом случае можно использовать содержание зерен (форменных элементов) или соотношение зерен и заполнителя (микрит+цемент). Прямая корреляция этих параметров с коэффициентом пористости (Кп), а иногда и коэффициентом проницаемости (Кпр) будет отражать седиментационный контроль формирования коллекторских свойств пород (рис. 3).

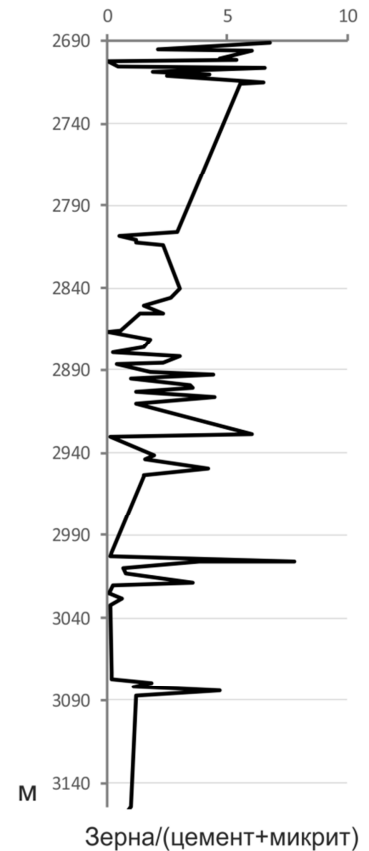

Зерна/(цемент+микрит)

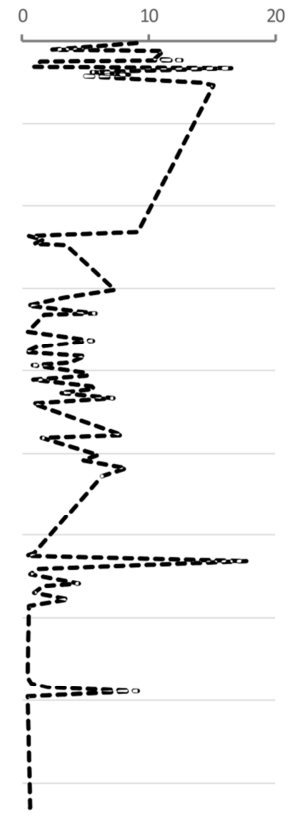

Коэффициент пористости

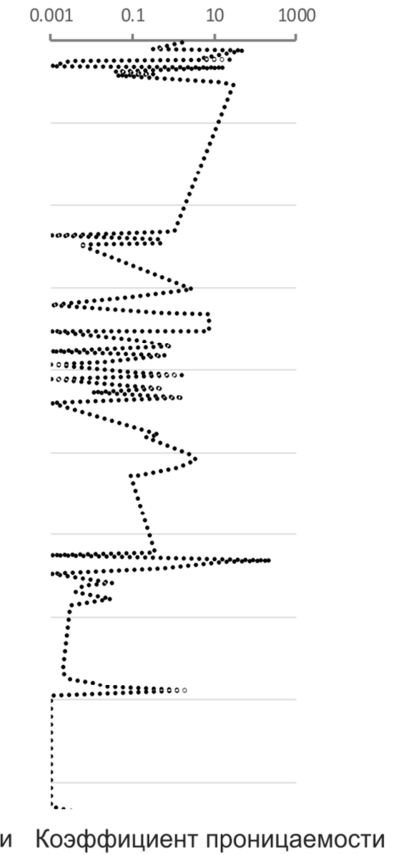

Рuc. 3. Корреляция «зернистости» карбонатных породы с пористостью и проницаемостью по разрезу скважины
В этом случае, согласно приведенному алгоритму действий, следует перейти к более подробному рассмотрению структурных типов пород, т.е. соотношению различных структурно-генетических типов зерен. Эти признаки являются ключом к интерпретации обстановок осадкообразования или простейшей литотипизации разреза. Как правило, фациальная интерпретация проводится не для всего разреза скважин, а для определенных, желательно достаточно узких стратиграфических интервалов. Пример представления данных показан на рис. 4.

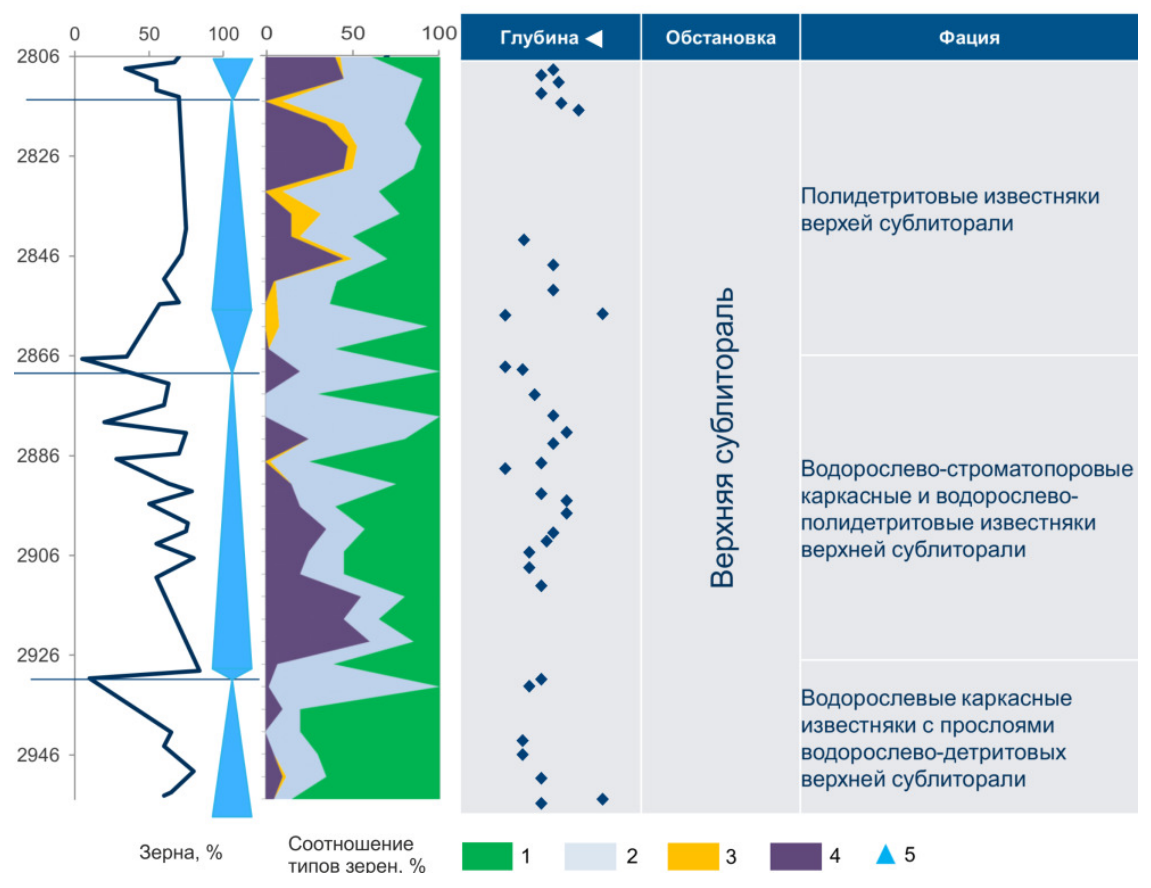

Puc. 4. Фациальная интерпретация на основе соотношения структурных типов зерен карбонатных пород разреза. Условные обозначения: зерна 1 - каркасные водорослевые; 2 - биодетрит; 3 биодетрит (преимущественно фораминиферы); 4 - микритовые зерна (пелоиды); 5 - трансгрессивнорегрессивные циклы. 
Известно, что для большинства карбонатных пластов, залегающих на больших глубинах, коллекторские свойства контролируются вторичными процессами. На примере олигоцен-миоценового карбонатного разреза, представленного преимущественно полидетритовыми и микритово-полидетритовыми известняками (рис. 5) видно, что преобладает обрат- ная зависимость между содержанием форменных элементов и коэффициентом пористости. При этом двумя доминирующими вторичными процессами являются доломитизация и сульфатизация. Стадиальный анализ показывает их синхронность, которая соответствует процессу по реакции Гайдингера: $2 \mathrm{CaCO}_{3}+\mathrm{MgSO}_{4} \rightarrow \mathrm{CaMg}\left(\mathrm{CO}_{3}\right)_{2}+\mathrm{CaSO}_{4}$.

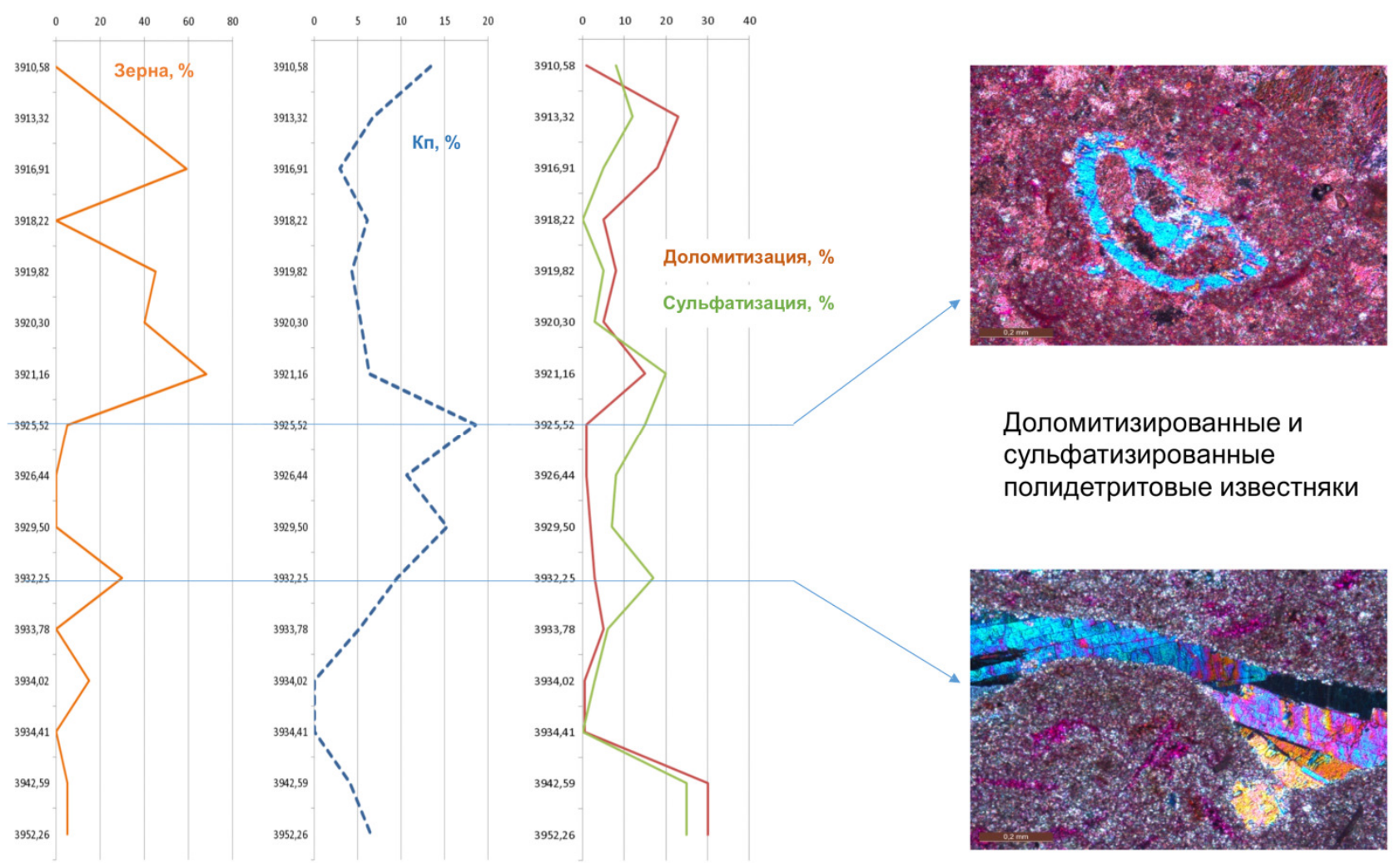

Puc. 5. Зависимость между пористостью, первичными и вторичными признаками карбонатных пород олигоцена-миоцена.

Вторичные процессы максимально проявлены в породах, которые характеризовались максимально хорошими первичными коллекторскими свойствами и также максимально утратили их в результате доломитизации - сульфатизации.

Итак, седиментационные (первичные) признаки пород позволяют реконструировать палеогеографические условия осадконакопления, а эпигенетические (вторичные) оценить основные факторы, определяющие его фильтрационно-емкостную неоднородность, а, следовательно, и качество прогнозируемого резервуара.

Последовательность изменения вещественноструктурных параметров пород по разрезу, отраженная в табличной форме, позволяет перейти к формализованному выделению слоевых последовательностей пород, а сопоставление числовых петрографических данных с петрофизическими помогает выявлять границы неоднородностей в пределах резервуара. Для обобщения литологических и петрофизических параметров в настоящее время отсутствуют целевые программные продукты. Петрофизиками ООО «Газпромнефть НТЦ» адаптирован перевод числовых литоло- гических параметров в программный комплекс Тесh$\log$ (Schlumberger), предназначенный для петрофизической интерпретации (рис. 6).

Подобный подход позволяет повысить качество и эффективность работ, связанных с геологическим моделированием, облегчает статистические расчеты, стандартизирует аналитические процедуры.

\section{Заключение}

Карбонатные резервуары нефтяных месторождений, прогнозируемые и разрабатываемые в настоящее время, как правило, сложены коллекторами сложного типа $[3,4]$. При обязательном фациальном анализе, заложенном в процедуру геологического моделирования, необходимо четко осознавать роль тех или иных литогенетических процессов. Предложенная методика количественной петрографической оценки карбонатных пород является одним из методов, позволяющих сделать это оперативно. Числовой формат представления петрографических данных позволяет:

1. Проводить оценку генетических причин формирования пустотного пространства;

2. Численно моделировать фации; 


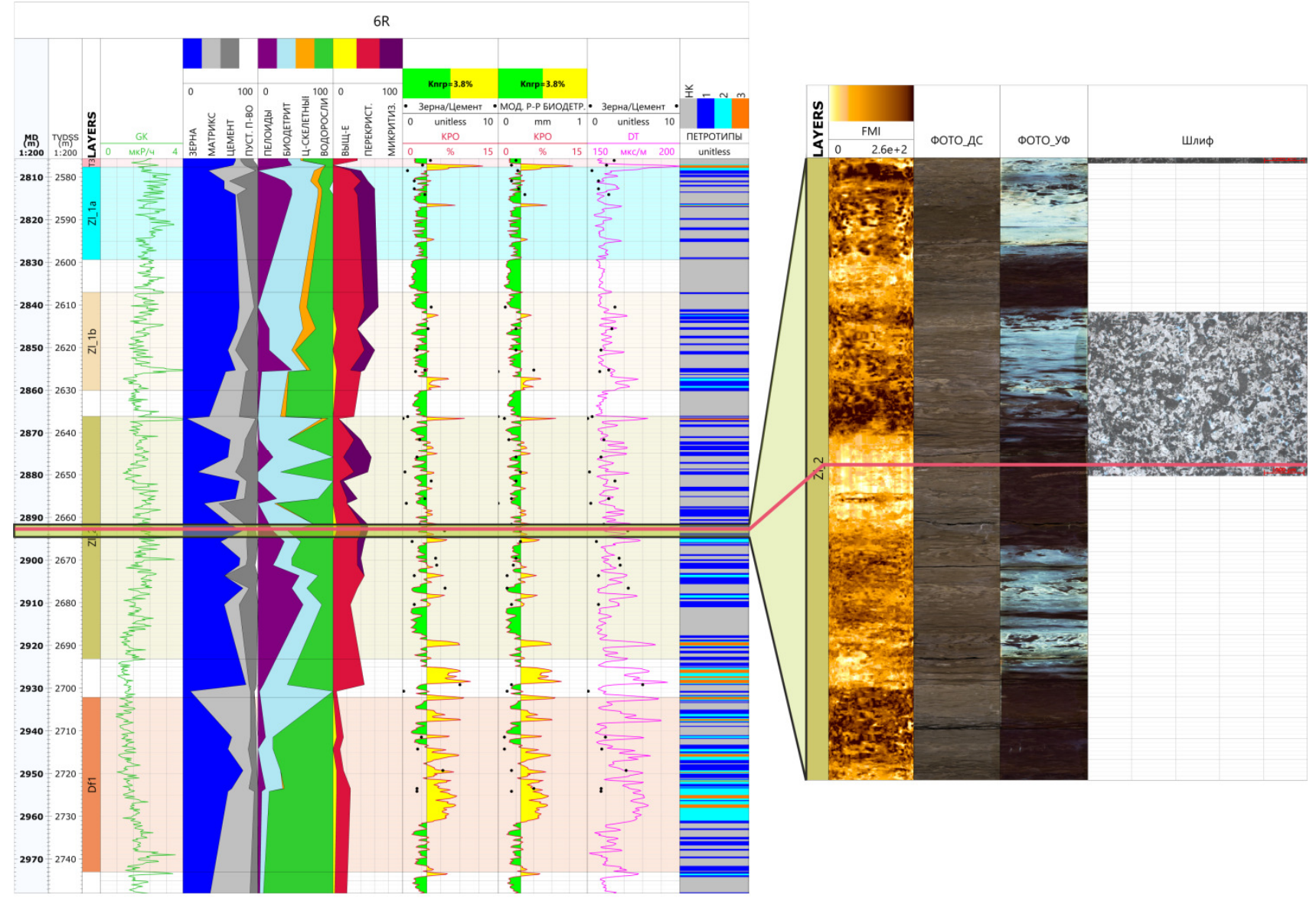

Puc. 6. Пример представления литологических и петрофизических данных в программном комплексе Techlog (Schlumberger).

3. Ограничить терминологические дискуссии (выбор классификаций для названий пород);

4. Создать фактологическую основу для 3D моделей;

5. Создать цифровую базу для решения любых задач стандартизации аналитических данных (систематизации, типизации, селекции, др.);

6. Сократить риски, связанные с отсутствием опыта геолога-модельера.

\section{ЛИТЕРАТУРА}

1. Методика отображения в цифровой геологической модели литолого-фациальных особенностей терригенного коллектора / В. П. Мангазеев [и др.] // Нефтяное хозяйство. - 2006. - № 5. - С. 66-70.

\section{ООО «Газпромнефть НТЦ», г. Санкт-Петербург}

Тугарова Марина Александровна, доктор геологоминералогических наук, эксперт Email: Tugarova.MA@gazpromneft-ntc.ru Тел.: +7 (812) 3136924 (доб. 3059)

Максимова Елизавета Никитична, ведущий специалист Email: Maksimova.EN@gazpromneft-ntc.ru Тел.: +7 (812) 3136924 (доб. 3112)

Идрисова Светлана Айратовна, главный спещиалист Email:Idrisova.SA@gazpromneft-ntc.ru;

Тел.: +7 (812) 3136924 (доб. 3729)
2. Методические рекомендации по изучению и прогнозу коллекторов нефти и газа сложного типа / Под ред. М. Х. Булач, Л. Г. Белоновской. - Л.: ВНИГРИ, 1989. - 103 с.

3. Цифровой керн. Комплексирование данных петрографических исследований карбонатных пород с результатами изучения керна / С. А. Идрисова [и др.] // PROHЕФТЬ. Профессионально о нефти. Журнал «Газпром нефти». 2018. - №2 (8) июнь. - С. 36-41.

4. Максимова, Е. Н. Литологическое обоснование петрофизической неоднородности карбонатных породколлекторов заволжского горизонта Балейкинского месторождения (Оренбургская область) [Электронный ресурс] / Е. Н. Максимова, М. А. Тугарова, Е. В. Стремичев // Нефтегазовая геология. Теория и практика. - 2019. - Т.14. - №1. Режим доступа: http://www.ngtp.ru/rub/2019/3_2019.html. (дата обращения: 10.06.2019).

\section{Ltd «Gazpromneft STC», Saint Petersburg}

Tugarova M. A., Doctor of Geological and Mineralogical Sciences, expert

Email: Tugarova.MA@gazpromneft-ntc.ru Tel.: +7 (812) 3136924 (ext. 3059)

Maksimova E. N., lead specialist

Email: Maksimova.EN@gazpromneft-ntc.ru

Tel.: +7 (812) 3136924 (ext. 3112)

Idrisova S.A., chief specialist

Email: Idrisova.SA@gazpromneft-ntc.ru

Tel.: +7 (812) 3136924 (ext. 3729) 